\title{
High correlation between winter precipitation and air temperature in heavy-snowfall areas in Japan
}

\author{
Yukari TAKEUCHI, Yasoichi ENDO, Shigeki MURAKAMI \\ Tohkamachi Experimental Station, Forestry and Forest Products Research Institute, Tohkamachi 948-0013, Japan \\ E-mail: yukarit@affrc.go.jp
}

\begin{abstract}
Long-term data of winter air temperature and precipitation were analyzed and the correlation between them investigated in order to identify the factors influencing snow reduction during the recent warmer winters in the heavy-snowfall areas in Japan. A high negative correlation between winter precipitation and air temperature was identified in the heavy-snowfall areas on the Sea of Japan side in the center of the main island (Honshu). It was confirmed that precipitation is mainly caused by cold winter monsoons, and thus correlates to a large extent with air temperature in these areas. The precipitation decrease can be considered an effective factor for the recent reduction in snow as well as the snowfall to precipitation ratio. This should be taken into account for a better prediction of snow reduction in relation to global warming.
\end{abstract}

\section{INTRODUCTION}

Global warming has become a major world issue over the past decade. In Japan, the decrease in snowfall and snow depth in snowy areas has been reported in relation to recent winter warming (Nakamura and Shimizu, 1996; Nakamura and Abe, 1998; Nakamura and others, 2000; Suzuki, 2006). The mean air temperature in January and February for the 30 year period 1971-2000 was found to be higher than that for 1961-90 at all the observation sites in snowy areas throughout Japan. The bimonthly maximum snow depth for the same period slightly increased at a number of sites, but decreased significantly at others, particularly in heavysnowfall areas on the Sea of Japan side (Ishizaka, 2004). The above-mentioned studies emphasize the relationship between winter air temperature and snow depth or snowfall, but without discussing the factors in the relationship in detail.

A large part of the Japanese snowy areas belongs to a temperate climate zone. As the mean winter air temperature is around the discriminating temperature between snow and rain, the ratio of snow to rain is sensitive to increase in air temperature. Ogawa and Nogami $(1994,1997)$ calculated the discriminating temperature between snow and rain, and estimated the changes in snowfall in Japan owing to global warming. Inoue and Yokoyama (2003) predicted changes in snowfall, maximum snow depth and snow-cover conditions using five sets of predicted data derived from numerical experiments with general circulation models. The predicted precipitations varied, with an increase in precipitation in some datasets and a decrease in others. It is not certain whether precipitation, including both snow and rain, will increase or decrease in Japan as global warming progresses.

In this study, the data for winter air temperature and precipitation are analyzed and the correlation between them investigated. The objective is to identify the factors that have influenced the decrease in snow in recent warmer winters in Japanese heavy-snowfall areas and to acquire information useful for better predicting snow decrease with respect to global warming.

\section{DATA}

Meteorological data measured at Tohkamachi Experimental Station, Forestry and Forest Products Research Institute $\left(37^{\circ} 08^{\prime} \mathrm{N}, 138^{\circ} 46^{\prime} \mathrm{E} ; 200 \mathrm{ma.s.l}\right.$.), were mainly used for the analysis. Tohkamachi city is located on the Sea of Japan side near the central mountains in the main island of Japan (Honshu). There are heavy snowfalls, and the annual maximum snow depth at Tohkamachi is $>2 \mathrm{~m}$ on average. However, the monthly mean air temperature is higher than $0^{\circ} \mathrm{C}$ except in January, and rainfall sometimes occurs even in winter. Observations started in 1917, and long-term data for 90 years are available. Data from all the 55 manned observation sites of the Japanese Meteorological Agency in the snowy areas were utilized. The altitudes of 48 of the sites are less than $200 \mathrm{~m}$, and the other sites are located from 200 to $1000 \mathrm{~m}$ a.s.l. The durations of data ranged from 44 to 134 years (90years on average). In addition, the data obtained by the Automated Meteorological Data Acquisition System (AMeDAS) of the same agency around Tohkamachi were used. The AMeDAS sites are located close together, but data durations are at most 30 years or more.

\section{RESULTS AND DISCUSSIONS}

\section{Long-term variations of snow depth, air temperature} and precipitation at Tohkamachi

Variations in the annual maximum snow depth, mean air temperature and precipitation during winter from December to February at Tohkamachi are shown in Figure 1. The maximum snow depth fluctuates widely, exceeding $3 \mathrm{~m}$ in some years and not reaching $1 \mathrm{~m}$ in others. Particularly notable is the decrease in the maximum snow depth since 1988. Hirota and others (2006) pointed out that the timing of snow reduction in the Hokuriku area on the Sea of Japan side in the center of the main island coincided with a decrease in the amount of drift ice in the southern part of the Sea of Okhotsk and a decrease in the soil-frost depth in the Tokachi area, Hokkaido island. The coincidence was seen as possibly showing a connection between the continentalscale atmospheric circulation and specific regional phenomena such as snowfall, sea ice and soil-frost depth.

The winter air temperature at Tohkamachi has increased at a rate of $1.5^{\circ} \mathrm{C}(100 \mathrm{a})^{-1}$, with a significantly high correlation coefficient of 0.41 (Fig. $1 \mathrm{~b}$ ). The relationship between the recent decrease in snow depth and increase in air temperature has been reported as described above. In this 

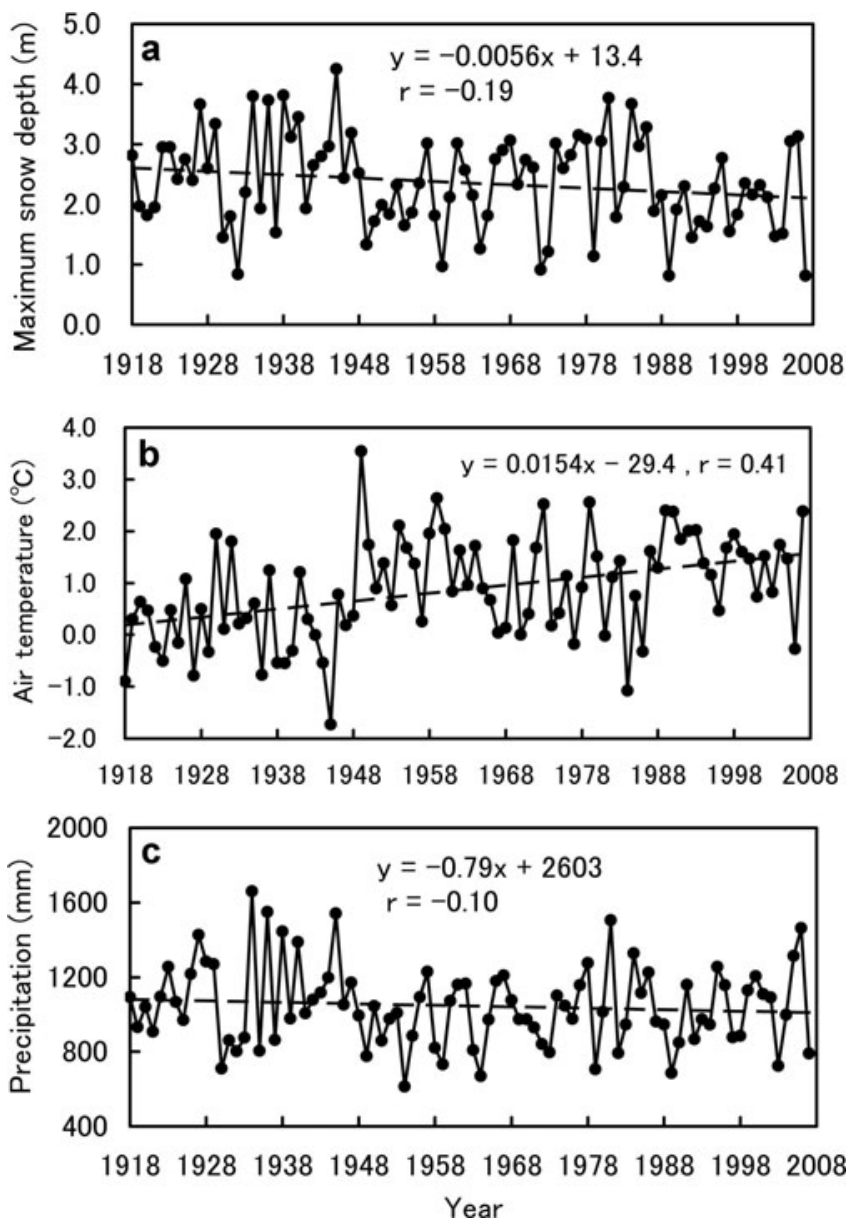

Fig. 1. Variations in the annual maximum snow depth (a), mean air temperature (b) and precipitation (c) during winter from December to February at Tohkamachi. The solid line is the decadal mean (a). The dashed lines are approximated lines $(b, c)$.

study, the variation in winter precipitation is also investigated (Fig. 1c). The decreasing trend in winter precipitation is not very distinct to date, with a correlation coefficient of -0.10 . However, the inverse phase between air temperature and precipitation is obvious in the figure.

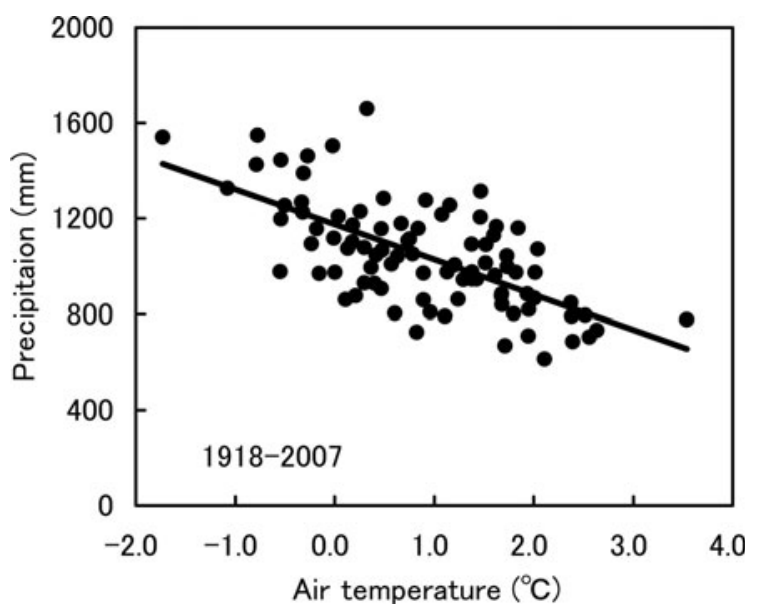

Fig. 2. Relationship between mean air temperature and total precipitation during winter at Tohkamachi, 1918-2007.

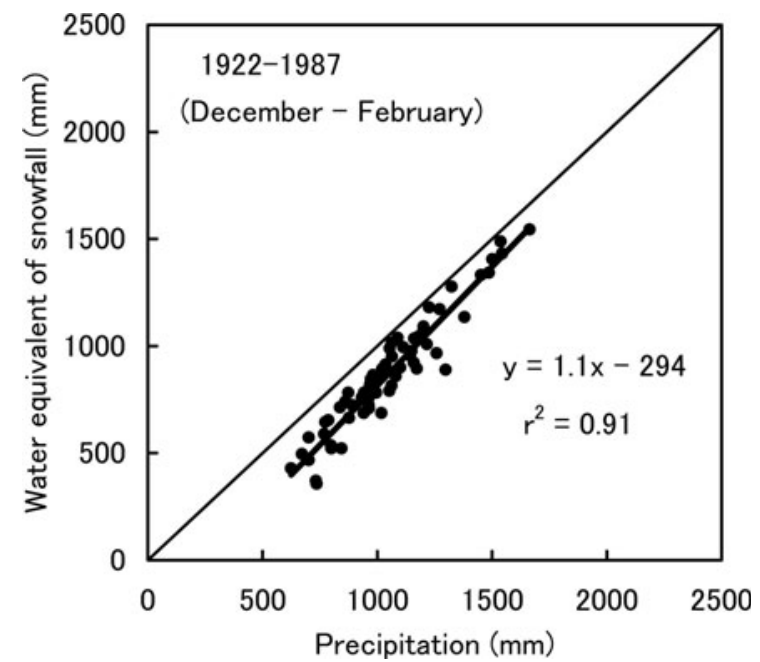

Fig. 3. Relationship between winter precipitation and water equivalent of snowfall at Tohkamachi, 1922-87.

\section{Relationship between air temperature and precipitation during winter}

The relationships between mean air temperature and total precipitation from December to February at Tohkamachi for 90 winters are shown in Figure 2. A distinct negative correlation is apparent (correlation coefficient is -0.66). This implies that the total precipitation, including rain as well as snow, decreases with an increase in winter air temperature.

To investigate the ratio between snow and rain, the relationship between precipitation and the water equivalent of snowfall is shown in Figure 3. The water equivalent of snowfall was obtained from the precipitation discriminated into snow and rain by visual observation (Yamamoi and others, 2000). The inclination of the approximate line, 1.1 (nearly equal to 1.0), implies that the amount of rain changes little depending on the precipitation at Tohkamachi. Consequently, the year-to-year variation in winter precipitation depends on the amount of snowfall in the case of Tohkamachi. Similar data were obtained in a mountainous area in the southwest of Niigata Prefecture (Matsuura and others, 2005).

\section{Regional characteristics of the correlation between winter air temperature and precipitation}

The correlation coefficients between winter air temperature and precipitation are expected to differ among the regions. They were calculated using the long-term data of 56 manned observation sites in the snowy areas throughout Japan (Fig. 4). The open and solid circles indicate positive and negative correlation coefficients, respectively. The large circles indicate correlations higher than 0.30, and small circles indicate lower correlations. At approximately $68 \%$ of the observation sites in the snowy areas, little correlation was found, while positive correlations were found for 6 sites $(11 \%)$ and negative correlations for 12 sites (21\%). Most of the negative correlations were clustered in the Hokuriku area, which includes the southwest half of Niigata Prefecture on the Sea of Japan side in the center of the main island. Absolute values for this area were quite high, the highest value, -0.66 , being for Tohkamachi.

The mean winter precipitations at the 56 sites were plotted against the correlation coefficients for each site as 


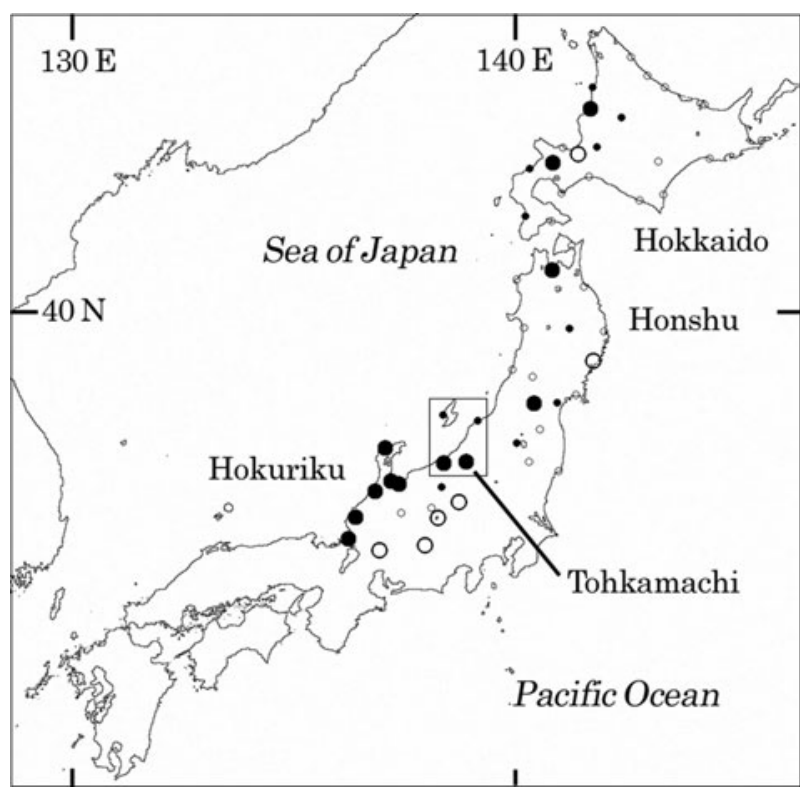

Fig. 4. Positions and correlation coefficients of 56 manned observation sites in the snowy areas of Japan. Open and solid circles indicate positive and negative correlation coefficients, respectively. Large circles indicate correlations whose absolute values are higher than 0.30. The boxed area is the area shown in Figure 6.

shown in Figure 5. The sites located in the Hokuriku area are circled by dots. Higher negative correlations are seen for the sites with precipitation $>600 \mathrm{~mm}$, which are clustered in the Hokuriku area. As a huge amount of precipitation occurs in this so-called heavy-snowfall area during winter, the effects of the decrease in precipitation with the increase in air temperature are considered to become more significant.

\section{Relationship between prevailing wind direction and precipitation}

Generally, a cold, dry winter monsoon blows from the Asian continent to Japan during winter. Heat and vapor are carried from the relatively warm sea surface to the atmospheric

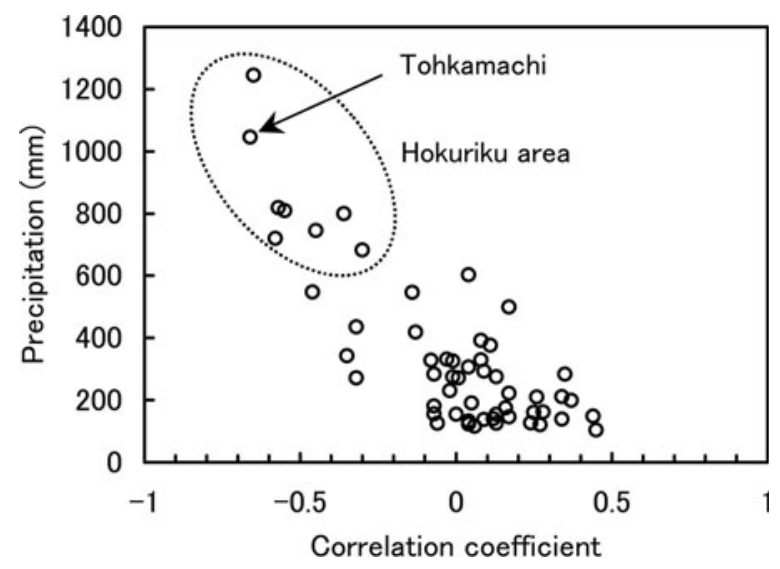

Fig. 5. Relationship between mean winter precipitation and correlation coefficient for each observation site. Data enclosed by dots are for sites in the Hokuriku area.

bottom layer over the Sea of Japan. This causes a decrease in the stability of the lower atmosphere, the occurrence of cumulonimbus, and heavy snowfall on the Sea of Japan side. It is well known that heavy snowfalls on the Sea of Japan side are brought during the intensification of typical winter synoptic patterns, which are characterized by high pressure over Siberia (Siberian high) and low pressure over the Pacific (Aleutian low). Cold-air advection from the north is another factor that leads to heavy snowfalls.

As stated above, the winter monsoon from the Asian continent is thought to affect the precipitation and air temperature in the heavy-snowfall areas in Japan. The relationship between the precipitation at Tohkamachi and the prevailing winds at 11 observation sites around Tohkamachi was therefore investigated using the data of the five winters 2003-07. The prevailing wind direction and mean wind speed at each site with daily precipitation more or less than $10.0 \mathrm{~mm}$ at Tohkamachi are shown in Figure $6 a$ and b, respectively. Similar results were obtained at almost all sites north and west of Tohkamachi. That is to say, when high precipitation
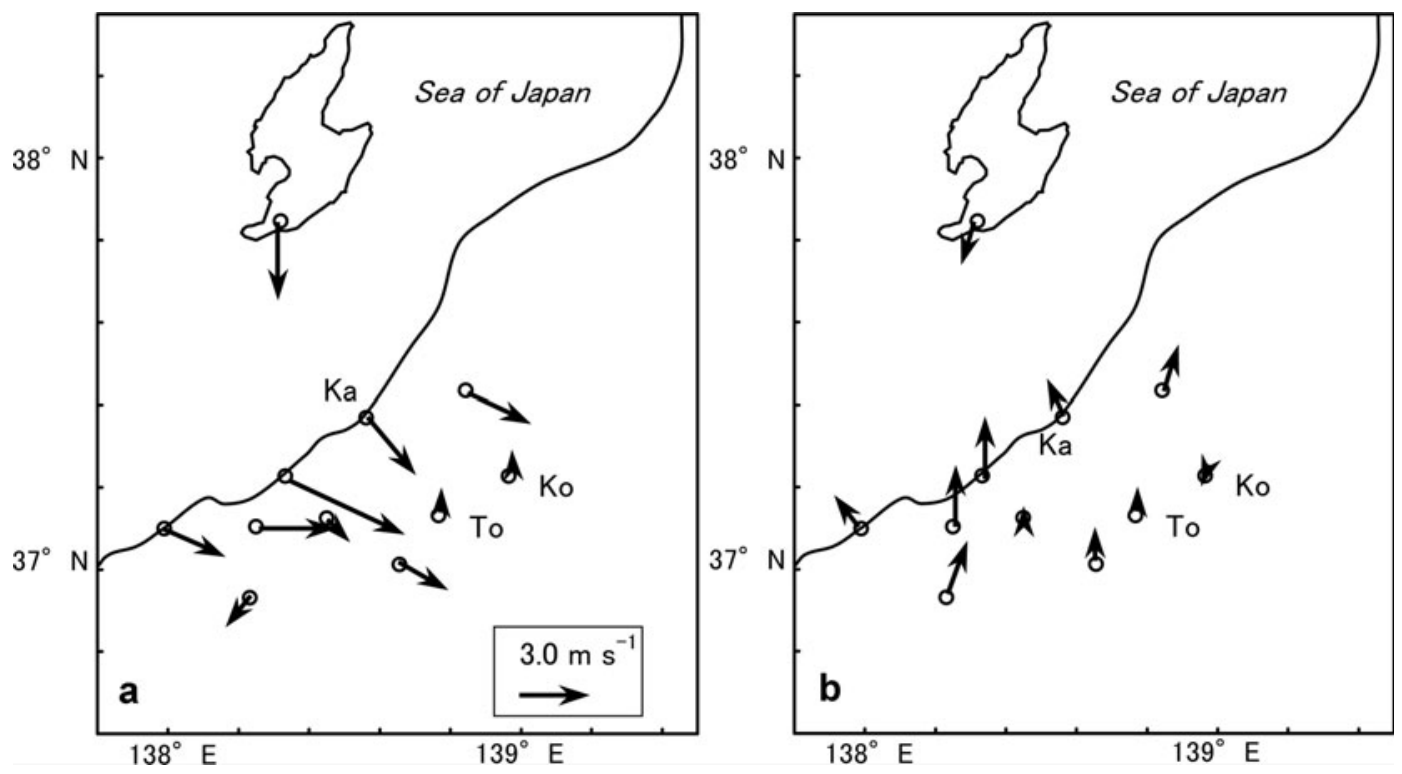

Fig. 6. Prevailing wind direction and mean wind speed at each observation site around Tohkamachi. Daily precipitation at Tohkamachi is (a) $>10.0 \mathrm{~mm}$, and (b) 0.0-10.0 mm. Ka: Kashiwazaki, To: Tohkamachi, Ko: Koide. 

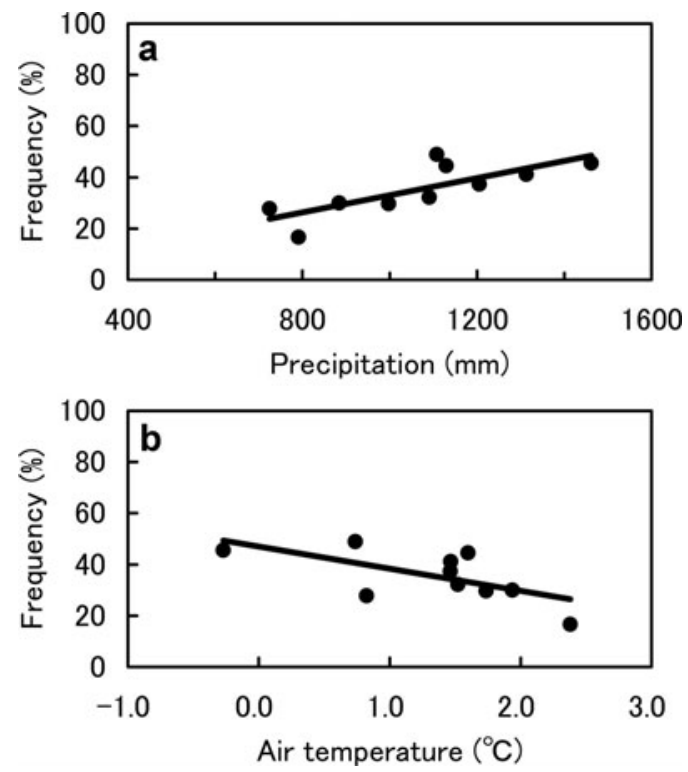

Fig. 7. Relationship between frequency of northerly and northwesterly winds at Kashiwazaki and (a) winter precipitation, and (b) mean air temperature at Tohkamachi from 1998 to 2007.

occurred at Tohkamachi, strong northwesterly winds prevailed; in contrast, when precipitation was low, the prevailing winds had a roughly southerly direction, and wind speed was small. The exceptions, such as Tohkamachi (' $\mathrm{To}^{\prime}$ ') and Koide ('Ko'), which are located on the riverside in the basins, are attributed to local topography (Rikiishi and Tojo, 2004).

In Figure 7, winter precipitation and mean air temperature at Tohkamachi for the past decade (1998-2007) are plotted against the frequency of northerly and northwesterly winds at the representative coastal site Kashiwazaki (marked as 'Ka' in Fig. 6), respectively. The results show that precipitation at Tohkamachi increases, and air temperature decreases, with an increase in frequency of northerly and northwesterly winds. This implies that both low air temperature and high precipitation are caused by the northerly and northwesterly monsoons, and this can explain the high negative correlation between air temperature and precipitation.

\section{CONCLUSIONS}

A high negative correlation between winter precipitation and air temperature was identified in the heavy-snowfall areas on the Sea of Japan side in the center of the main island. It was found that precipitation increases, and air temperature decreases, with an increase in frequency of northerly and northwesterly winds. This confirms that precipitation is mainly caused by a cold winter monsoon, and that precipitation thus correlates to a large extent with air temperature in heavy-snowfall areas such as Tohkamachi on the Sea of Japan side.

A precipitation decrease can be considered an effective factor for the recent reduction in snow as well as the snow to precipitation ratio. Winter precipitation associated with the winter monsoon can be regarded as a response to changes in the continental-scale atmospheric circulation. This process should be taken into account for a better prediction of snow reduction in the heavy-snowfall areas in Japan.

\section{ACKNOWLEDGEMENTS}

The long-term meteorological data of Tohkamachi Experimental Station were measured and arranged by S. Niwano and other transferred or retired staffs. The data of many meteorological observation sites were provided by the Japan Meteorological Agency. Part of this study was financially supported by a Grant-in-Aid for Scientific Research (Project No. 17710159) from the Ministry of Education, Culture, Sports, Science and Technology of Japan.

\section{REFERENCES}

Hirota, T. and 6 others. 2006. Decreasing soil-frost depth and its relation to climate change in Tokachi, Hokkaido, Japan. J. Meteorol. Soc. Jpn, 84(4), 821-833.

Inoue, S. and K. Yokohama. 2003. Estimates of snowfall depth, maximum snow depth, and snow pack environments under global warming in Japan from five sets of predicted data. J. Agr. Meteorol., 59(3), 227-236.

Ishizaka, M. 2004. Climatic response of snow depth to recent warmer winter seasons in heavy-snowfall areas in Japan. Ann. Glaciol., 38, 299-304.

Matsuura, S., K. Matsuyama, S. Asano, T. Okamoto and Y. Takeuchi. 2005. Fluctuation of the seasonal snowpack in a mountainous area of the heavy-snow district in the warm-temperate zone of Japan. J. Glaciol., 51(175), 547-554.

Nakamura, T. and O. Abe. 1998. Variation in amount of snow, winter precipitation and winter air temperatures during the last 60 years in Shinjo, Japan. Natl. Res. Inst. Earth Sci. Disaster Pre. Rep. 58, 1-14.

Nakamura, T. and M. Shimizu. 1996. Variation of snow, winter precipitation and winter air temperature during the last century at Nagaoka, Japan. J. Glaciol., 42(140), 136-140.

Nakamura, T., O. Abe, M. Shimizu and T. Ohata. 2000. Changes in snow in Japan with global warming. In Watanabe, Y. and T.B.M.J. Ouarda, eds. Proceedings of the International Workshop on River Environments Considering Hydraulic and Hydrologic Phenomena in Snowy and Cold Regions, 20-24 March 2000, Québec, Canada. Tokyo, Japan Society of Civil Engineering, 25-30.

Ogawa, M. and M. Nogami. 1994. [Precipitation amount separated by precipitation type using discriminating temperature during winter season]. J. Jpn Soc. Hydrol. Water Resour., 7, 421-427. [In Japanese with English summary.]

Ogawa, M. and M. Nogami. 1997. [The effect of global warming to precipitation amount during winter season in Japan]. J. Jpn Soc. Hydrol. Water Resour., 10, 79-86. [In Japanese with English summary.]

Rikiishi, K. and Y. Tojo. 2004. [On the characteristics of snowfall in the Yokote Basin, Akita Prefecture.] Seppyo, J. Jpn Soc. Snow Ice, 66(5), 567-580. [In Japanese with English summary.]

Suzuki, H. 2006. [Long-term changes in snowfall depth and snowcover depth in and around Niigata Prefecture from 1927 to 2005: analysis using data observed at railway stations.] Tenki, 53(3), 185-196. [In Japanese with English summary.]

Yamamoi, K., Y. Endo, Y. Kominami, S. Niwano and Y. Ozeki. 2000. [Meteorological statistics during the past 80 years in Tohkamachi city, Niigata (1918-1997).] Bull. Forestry Forest Prod. Res. Inst. 377, 61-99. [In Japanese.] 